\title{
Evaluation of potential changes in hydrologically relevant statistics of rainfall in Southern Africa under conditions of climate change ${ }^{\#}$
}

\author{
TG Lumsden ${ }^{1 *}$, RE Schulze ${ }^{1}$ and BC Hewitson ${ }^{2}$ \\ ${ }^{1}$ School of Bioresources Engineering and Environmental Hydrology, University of KwaZulu-Natal, Private Bag X01, \\ Scottsville, 3209, South Africa \\ ${ }^{2}$ Climate Systems Analysis Group, Department of Environmental and Geographical Science, University of Cape Town, \\ Private Bag X3, Rondebosch, 7701, South Africa
}

\begin{abstract}
Scenarios of present, intermediate and future climates for Southern Africa were analysed to evaluate potential changes in hydrologically relevant statistics of rainfall that could be observed this century as a result of climate change. These climate scenarios were developed in previous studies by applying empirical downscaling techniques to relatively coarse-scale climate scenarios simulated by general circulation models (GCMs) as part of the Intergovernmental Panel on Climate Change $3^{\text {rd }}$ and $4^{\text {th }}$ Assessment Reports (TAR and AR4, respectively). The regional climate scenarios were available at a daily time-step and for a spatial grid resolution of $0.25^{\circ}$ over Southern Africa, comprising South Africa, Lesotho and Swaziland. In the study, the regional climate scenarios were related to the 1946 quaternary catchments in the region since the possible hydrological impacts of climate change will ultimately be assessed explicitly by applying the regional climate scenarios in a daily time-step hydrological model. The analysis of potential changes in hydrologically relevant rainfall statistics was qualitative in nature and focused on determining where convergence exists amongst the different climate models with respect to changes in rainfall, and what the likely hydrological implications would be for the region. According to all of the GCMs evaluated in the study, more rainfall is projected for the east of the region. The greater rainfall projected for the east would be in the form of more rain days and more days with bigger rainfalls. If these scenarios are correct, the combination of wetter antecedent conditions and larger rainfall events would result in more runoff being generated and this would have implications for, inter alia, filling of dams and water quality. According to all of the GCMs evaluated, less rainfall is projected along the west coast and the adjacent interior, with the possibility of a slight increase in inter-annual variability. If correct, this would result in a decrease in flows and an increase in flow variability, since changes in precipitation are amplified in the hydrological cycle. As convergence in climate-change scenarios becomes apparent, there is now an arguable basis for developing appropriate response strategies for incorporation into adaptation policy. Perhaps one of the greatest challenges in this regard is now to explore the issues of uncertainty and probability in order to develop a more rigorous basis to enable proactive responses.
\end{abstract}

Keywords: climate change, rainfall, rainfall statistics, hydrology, Southern Africa, South Africa

\section{Introduction}

A focus on potential impacts of climate change on the water sector of Southern Africa (i.e. the Republic of South Africa together with Lesotho and Swaziland) was triggered by a series of activities and events in the first few years of the new millennium which included the South African Country Study on Climate Change, the World Summit on Sustainable Development, the Intergovernmental Panel on Climate Change (IPCC) reports in 2001, the $3^{\text {rd }}$ and $4^{\text {th }}$ World Water Forums, as well as active South African participation in the International Geosphere-Biosphere Programme and the International Dialogue on Water and Climate, among others. Additionally, there was the realisation that perturbations in climate parameters, particularly of rainfall, were amplified by the hydrological

\footnotetext{
This paper (now modified) was originally presented at the 13th

SANCIAHS Symposium, 6-7 September 2007, Cape Town, South Africa

* To whom all correspondence should be addressed.

욜 +2733260 5486; fax: +2733260 5818;

e-mail: 1umsden@ukzn.ac.za

Received 16 May 2009; accepted in revised form 10 August 2009.
}

system and that if climate changes were to manifest themselves in the manner which international science was projecting, it would add a further layer of concern to the management of Southern Africa's already high-risk and stressed water sector, with potential implications to the entire region's socio-economic well-being, but particularly that of the poor.

Long-term changes in observed rainfall in South Africa have been noted in a number of studies. Some of these studies were focused on localised areas while others were focused at a national level. Lynch et al. (2001) noted a gradual increase in annual rainfall in the Potchefstroom area from 1925 to 1998, while Van Wageningen and Du Plessis (2007) noted a reduction in annual rainfall (with an accompanying increase in rainfall intensity) over the latter half of the $20^{\text {th }}$ century at Table Mountain, Cape Town. Mackellar et al. (2007) reported both wetting (central coastal belt, north-eastern areas) and drying (escarpment) over the Namaqualand region during the latter half of the $20^{\text {th }}$ century. At a national level, Richard et al. (2001) and Fauchereau et al. (2003) noted no overall wetting or drying, but did report an increase in inter-annual rainfall variability during the $20^{\text {th }}$ century. Warburton and Schulze (2005) reported that over the latter half of the $20^{\text {th }}$ century, median annual rainfall has decreased markedly over the Limpopo, 
North-West and into the Northern Cape Provinces along the border of South Africa with Botswana, with decreases evident in the south-eastern Free State as well, but with increases in the winter rainfall region.

The impact of climate change on future rainfall and water resources in South Africa has been studied utilising climate scenarios derived from GCMs. The South African Country Study on Climate Change (SACSCC) was the first study which involved South African scientists from a wide range of disciplines in assessing the issue of climate change at the national and key sectoral levels. The study formed one of the elements of South Africa's First National Communication to the United Nations Framework Convention on Climate Change, and the National Climate Change Response Strategy. The vulnerability and adaptation component of the study (Kiker, 2000) utilised 3 GCMs. The HadCM2 GCM projected that summer rainfall will decrease over most of the country (changes ranged between a $15 \%$ decrease to a $5 \%$ increase) while the Genesis Model projected an increase for most of the country (Perks et al., 2000). CSM projections were similar to HadCM with changes ranging between a $10 \%$ increase and $10 \%$ decrease. Winter rainfall was projected by CSM to decrease by more than $25 \%$ in the northern part of the country, and increase slightly in the southwestern part, while HadCM2 projected a similar pattern, but a $25 \%$ decrease in the south-western areas. Genesis simulated an increase in winter rainfall over most of the country (Perks et al. 2000). Although a significant study at the time, the results produced during the SACSCC are now somewhat dated.

More recently the South African Water Research Commission (WRC) has funded 2 successive multi-institutional projects to investigate the potential impacts of climate change on South Africa's water sector. The development of climate scenarios for future and present conditions, at a relatively high spatial and temporal resolution, has been a focus in these projects. In the first of the projects, regional climate scenarios for a present (1975 to 2005) and future (2070 to 2100) climate were produced at a 0.5 degree spatial resolution for Southern Africa using the Conformal-Cubic Atmospheric Model (C-CAM) (Engelbrecht, 2005). Lower boundary forcing was obtained from the CSIRO Mk3 Ocean-Atmosphere GCM, which was integrated for the period 1961 to 2100 with increasing greenhouse gas concentrations. Potential changes in the regional climate, from present to future conditions, were evaluated in terms of changes in 'hydrologically relevant' rainfall statistics (Schulze et al., 2005). The potential impact of climate change on hydrological responses was then subsequently explicitly assessed by applying the daily timestep regional climate scenarios in a daily hydrological model (Schulze et al., 2005). The results of the analysis of changes in rainfall over the region showed that a strong reduction (of up to $70 \%$ ) in rainfall was likely over the west coast and adjacent interior. Over south-eastern parts of the region a slight increase in rainfall was projected (less than $10 \%$ ), while the rest of the region was projected to experience either no change, or a slight reduction in rainfall (less than $10 \%$ ). At the time of performing the analyses reported in Schulze et al. (2005), regional climate scenarios from only one climate model were available. This was a limitation of the study since it is considered important in climate-change impact studies to consider climate projections derived from a number of climate models in order to better characterise the envelope of possibilities.

At a later stage in the course of the above WRC-funded project, however, and in the one succeeding it, regional climate scenarios derived from a number of GCMs were subsequently produced (Hewitson et al., 2005a). These regional climate scenarios were developed by empirically downscaling GCM simulation output, and were produced at a quarter degree spatial resolution for Southern Africa. At the time of conducting the research reported in this paper, regional climate scenarios derived from $6 \mathrm{GCMs}$ had been produced at a daily time-step for climate-change impact assessments in Southern Africa. These scenarios have been evaluated in terms of future vs. present changes in hydrologically relevant rainfall statistics, and will later be applied with a daily hydrological model to explicitly assess the potential impact of climate change on hydrological responses.

In this paper, the evaluation of the future vs. present changes in hydrologically relevant rainfall statistics, as derived from the 6 abovementioned GCM scenarios, is presented. Apart from determining where convergence exists amongst the different GCMs, the qualitative analysis of changes also focuses on exploring the likely implications for the Southern African water sector.

\section{Methodology}

\section{Regional climate scenarios}

The GCMs used to develop the global climate scenarios which were downscaled to a quarter degree resolution spatial grid for Southern Africa for application in this research, included 3 from the IPCC $3^{\text {rd }}$ Assessment Report (IPCC, 2001), and 3 from the World Climate Research Programme's Coupled Model Intercomparison Project Phase 3 (CMIP3) multi-model dataset used in the IPCC $4^{\text {th }}$ Assessment Report (IPCC, 2007) - the CMIP 3 Archive. The GCMs are as follows:

\section{- CSIRO}

- ECHAM

- HadAM

- GFDL

- MIROC

- MRI-CGCM

The first 3 GCMs in the above list were employed in the IPCC $3^{\text {rd }}$ Assessment Report (TAR), while the remaining 3 were employed in the $4^{\text {th }}$ Assessment Report (AR4). The future global climate scenarios were simulated based on the A2 emissions scenario defined by the IPCC Special Report on Emission Scenarios (SRES) (Nakićenović and Swart, 2000). This scenario of greenhouse gas emissions assumes that efforts to reduce global emissions this century are relatively ineffective. Regardless of the emission scenario selected, a further increase of at least $0.6^{\circ} \mathrm{C}$ in global mean temperature is likely, owing to past greenhouse gas emissions (Hewitson et al., 2005b).

Two methods are commonly employed in downscaling global climate-change scenarios to produce regional scenarios; downscaling with regional climate models (RCMs) embedded within the low resolution GCM fields, and empirical downscaling forced by the GCM fields (Hewitson et al., 2005b). The IPCC TAR reviews these approaches and their relevant strengths and weaknesses concluding that, while they have different attributes, they are nonetheless of comparable skill. In the long term, it is likely that both methods will remain of value in different contexts. However, at present it is arguable that the empirical downscaling approach is the more mature of the 2 in developing climate-change projections for immediate use by the impacts community, if for no other reason than that practical exploration of the projected climate change envelope 
is possible owing to the substantially lower computational requirement. Empirical downscaling was therefore employed in the production of the regional climate scenarios evaluated in this study. Empirical downscaling techniques involve deriving relationships between synoptic scale and local climates using observational data, and then applying these relationships to GCM output to generate higher resolution regional climate scenarios (Hewitson et al., 2005b).

Regional scenarios were developed for present, intermediate future and more distant future climates represented by the following time periods (Hewitson et al., 2005a):

- Present climate: \pm 1960 to 1990 for both AR4 and TAR models

- Intermediate future climate: \pm 2046 to 2065 for AR4 models only

- Distant future climate: \pm 2081 to 2100 for AR4 models; \pm 2070 to 2100 for TAR models

All the above regional scenarios included a daily time series of rainfall for each climatic period and the \pm denotes that the respective scenarios derived from the different GCMs were not for identical time periods.

In this paper, more emphasis was placed on assessing the possible changes in rainfall under the intermediate future climate, rather than the distant future climate. The reason for this is that the distant future climate is more dependent on the emission scenario adopted than the intermediate one, and is thus subject to greater uncertainty. It is also easier for most individuals to relate to a time period that commences \pm 40 years from now, rather than a period that commences \pm 70 years from now.

\section{Linking regional climate scenarios to quaternary catchments}

Since the possible hydrological impacts of climate change will ultimately be assessed explicitly by applying the regional climate scenarios in a daily time-step hydrological model, the assessment of possible changes in hydrologically relevant rainfall statistics presented in this paper was performed at a scale suitable for hydrological modelling in the region, this being the quaternary catchment (QC) scale. In this way the results of the analyses presented in this paper can inform a future, more detailed approach where a hydrological model is applied in assessments. In order to represent the regional climate scenarios at QC scale, pixels were selected from the $0.25^{\circ}$ regional scenario grids to represent each of the 1946 QCs in Southern Africa. In doing this, the $1^{\text {st }}$ step was to compare the relative scale of the regional climate grids to the QCs. In Fig. 1, a grid having the same resolution as the regional climate scenarios has been overlaid by a map of the QCs. A close-up view of the area highlighted by the blue rectangle in Fig. 1 is given in Fig. 2. Figure 1 shows that the larger QCs in the region (mostly in the more arid Northern Cape Province of South Africa) are generally greater in area than the climate scenario pixels, while in other areas, such as that shown in Fig. 2, the QCs and pixels have areas that are of a similar size. It was undesirable to simply average the data contained in the pixels falling within a catchment, since this would exacerbate the differences in temporal rainfall variability between climate model (areal) and station (point) rainfall data (Chen et al., 1996; Osborn and Hulme, 1997). Instead, the approach adopted was to assign a single representative pixel to each QC. In this regard, it was assumed that the pixel containing the centroid of a QC would be selected to represent that catchment. The time series of daily climate for

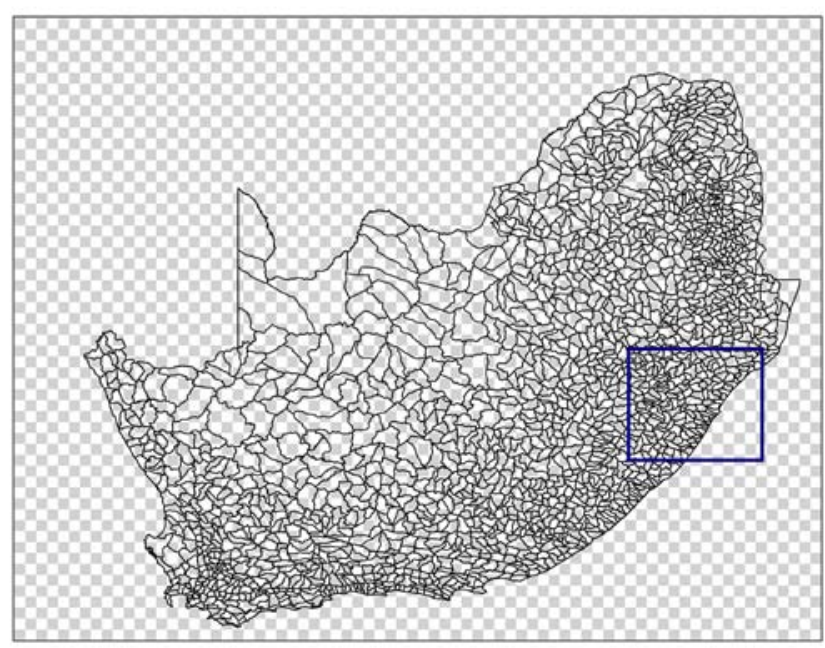

Figure 1

An $0.25^{\circ}$ resolution grid overlaid by the quaternary catchment boundaries

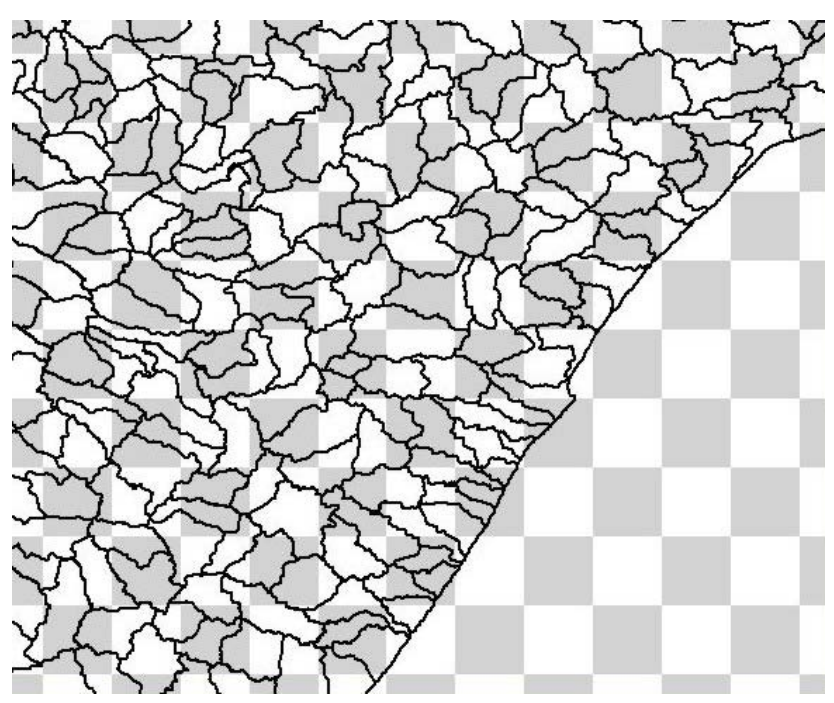

Figure 2

Close-up view of the area highlighted in Fig. 1

the various periods considered in the study were then extracted for the selected pixels from the set of available regional climate scenarios. Hydrologically relevant rainfall statistics were then calculated based on these time series as described in the following section. As explained previously, these time series could be directly input to a hydrological model in a future study to explicitly assess the hydrological impacts of climate change for the quaternary catchments.

\section{Hydrologically relevant rainfall statistics}

The hydrologically relevant statistics of rainfall assessed in this study focused on characterising the annual means and variances of the rainfall scenarios, as well as the distribution of daily rainfall amounts. The distribution of daily rainfall amounts was represented by determining the total number of days in the relevant daily time series on which rainfall either equalled or exceeded certain defined threshold amounts. This would give an indication of whether individual rainfall events are likely to be larger or smaller in future, than at present. It is 
a) Mean Annual Precipitation
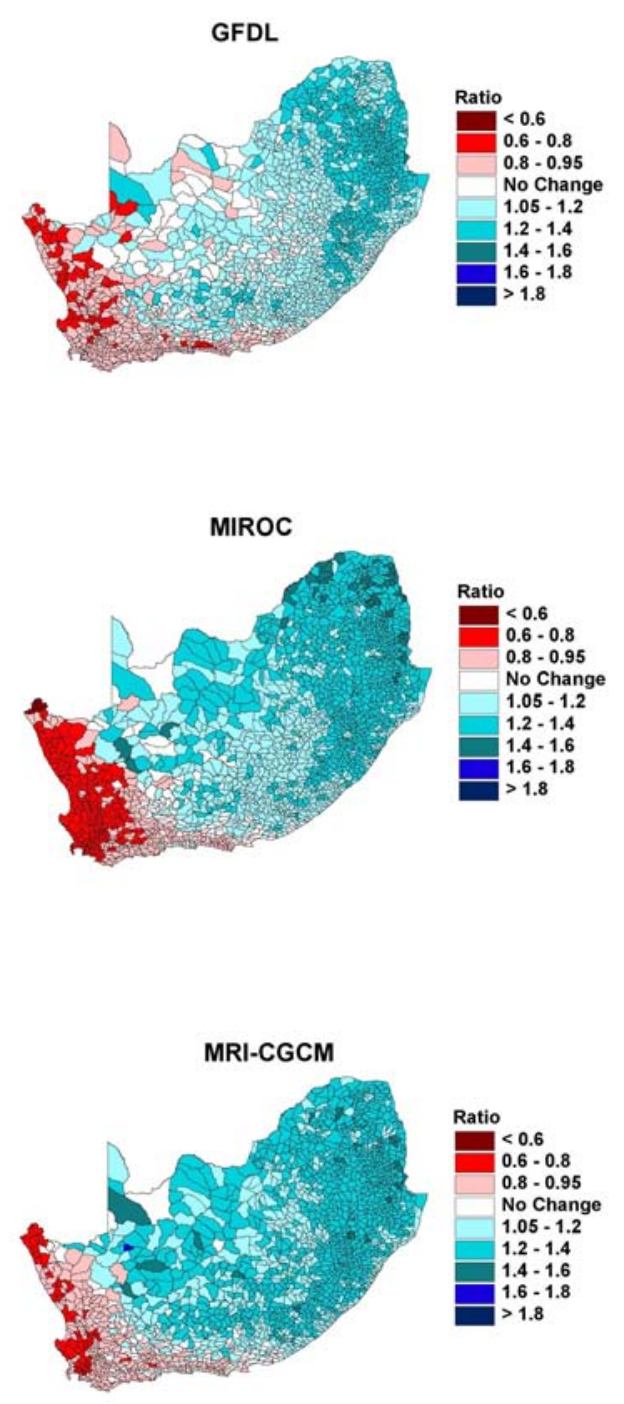

b) Coeff. of Variation of Annual Precipitation
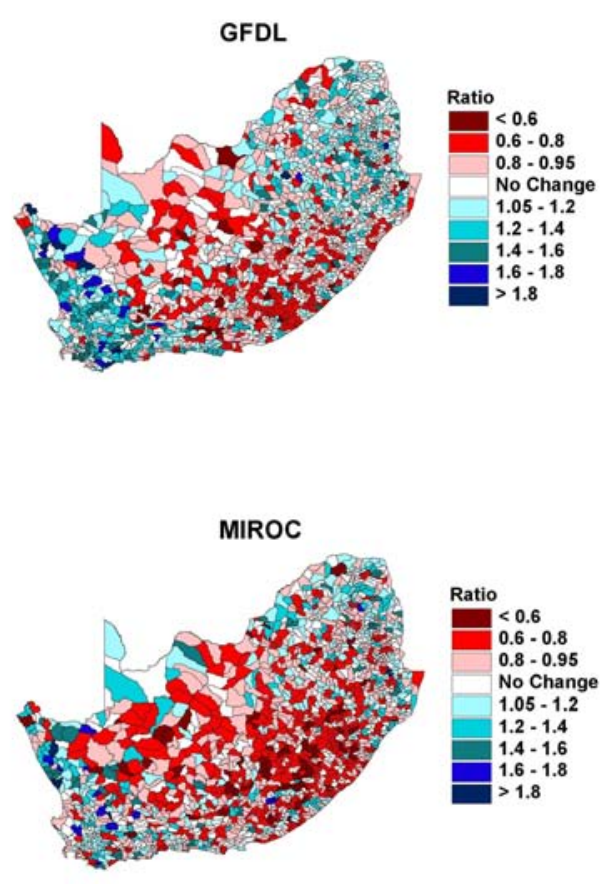

Figure 3 a\&b

Ratios of intermediate future to present climate rainfall statistics: a) mean annual precipitation and $b$ ) coefficient of variation of annual rainfall

intermediate threshold between zero and $10 \mathrm{~mm}$. The threshold of $20 \mathrm{~mm}$ was selected to represent heavier rainfall events associated with higher stormflows.

In order to make a fair comparison, the number of years of data considered in statistical calculations was kept the same when comparing the intermediate future and distant future climates to the present climate. Thus, for the regional scenarios derived from the AR4 GCMs, only 20 of the 30 years of available data in the present climate scenario were used in calculating statistics so as to be comparable with the 20 years of data available for the intermediate and distant future climates. The last 20 years of data from the 30-year present climate series were considered since the selection of this period resulted in a more equal spacing of the different climates over time.

\section{Results}

The potential changes in hydrologically relevant rainfall statistics are presented as maps of the ratio of the intermediate future (or distant

important to consider individual rainfall events, as these trigger key hydrological responses such as stormflow and sediment generation. The statistics that were selected included:

- Mean annual precipitation (MAP)

- Coefficient of variation (CV) of annual precipitation

- Total number of days in the time series with no rainfall

- Total number of days in the time series with more than $5 \mathrm{~mm}$ of rainfall

- Total number of days in the time series with more than $10 \mathrm{~mm}$ of rainfall

- Total number of days in the time series with more than $20 \mathrm{~mm}$ of rainfall.

Considering days with no rainfall vs. days with rainfall has significance in terms of general antecedent wetness. The threshold of $10 \mathrm{~mm}$ on a given day was considered in the distribution analysis since this is often viewed as a threshold for stormflow to occur, or for farmers not being able to implement mechanical field operations. The threshold of $5 \mathrm{~mm}$ was selected as an future, as the case may be) climate statistic to that of the present climate statistic. Thus, a ratio value of greater than 1 indicates an increase in that statistic over time (mapped in shades of green and blue), while a value of less than 1 indicates a decrease (mapped in shades of red and brown). A ratio in the range 0.95 to 1.05 was considered to be a negligible change and was indicated in the maps as un-shaded areas of 'No Change'. The ratios presented in the maps represent a more qualitative assessment of changes in rainfall (in direction and magnitude) rather than a quantitative, statistical assessment. A quantitative, statistical assessment was deemed to be less appropriate since the analyses focused mostly on the intermediate future climate for which climate scenarios were only available for $3 \mathrm{GCMs}$,

\section{Potential changes in hydrologically relevant rainfall statistics under an intermediate future climate}

The potential changes in hydrologically relevant rainfall statistics under an intermediate (mid- $21^{\text {st }}$ century) climate 
are presented in Fig.

3 for a) mean annual precipitation, b) $\mathrm{CV}$ of annual precipitation, c) total number of days with no rainfall, d) total number of days with rainfall exceeding 5 $\mathrm{mm} / \mathrm{d}, \mathrm{e}$ ) total number of days with rainfall exceeding $10 \mathrm{~mm} / \mathrm{d}$, and f) total number of days with rainfall exceeding $20 \mathrm{~mm} / \mathrm{d}$. The changes in Fig. 3 are all based on the regional climate scenarios derived from AR4 GCMs, since there were no regional climate scenarios derived from TAR GCMs for the intermediate future climate.

In Fig. 3a, the regional climate scenarios derived from the AR4 GCMs considered project a reduction in MAP on the west coast and adjacent interior of the region. This is bordered by a transition zone in the western interior where there are catchments experiencing little or no change in MAP. For the remainder of the region, a pattern of increasing MAP is evident. The MIROC scenario presents the driest scenario for the west (60 to $80 \%$ of present MAP), while the MRI-CGCM presents the wettest pattern in the east ( 20 to $40 \%$ higher MAP). The GFDL scenario appears to be a 'middle-of-the-road' scenario.

In Fig. 3b, there are no obvious patterns in the changes in inter-annual variability of rainfall in the various regional scenarios, although there is a slight tendency towards higher variability where MAP was projected to decrease, i.e. along the west coast and adjacent interior.

In terms of changes in the distribution of daily rainfall amounts, all scenarios project an increase in the number of rainless days in a small area in the South Western Cape, and a decrease in the number of days in the eastern half of the region (Fig. 3c). For the remainder of the region there is no change evident in the number of rainless days. In the map of the number of days with more than $5 \mathrm{~mm}$ of rainfall (Fig. 3d), all scenarios project a decrease in the number of days in the west, while there is an increase in the central and eastern parts, and a transition zone in the western interior. This map displays similar patterns and magnitudes of change to the map for MAP (Fig. 3a).
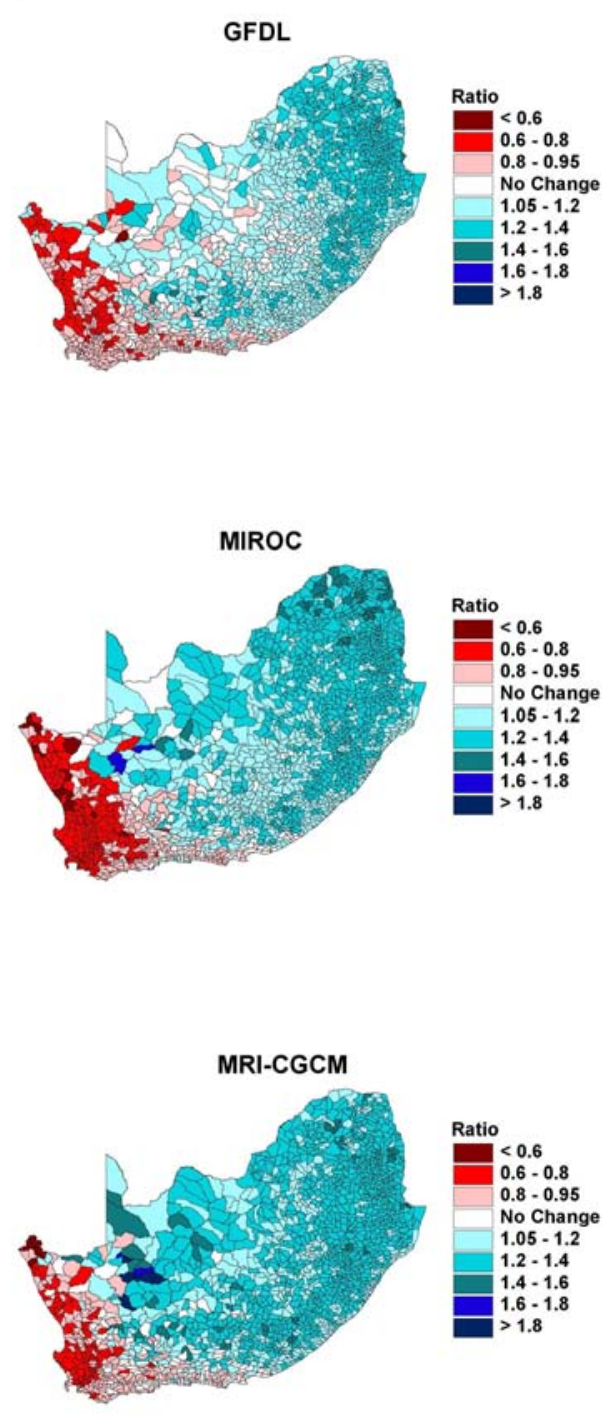

Figure $3 c \& d$
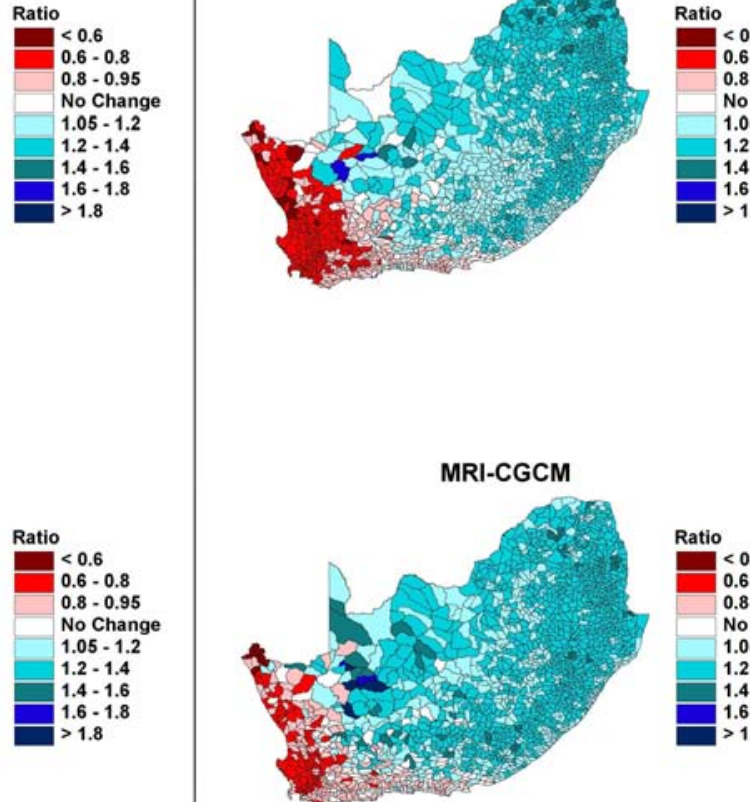

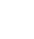

present climate rainfall statistics: c) total number of days with no rainfall and d) total number of days with rainfall $>5 \mathrm{~mm}$

In the maps of the number of days with more than 10 and $20 \mathrm{~mm}$ of rainfall (Figs. 3e and 3f, respectively), the scenarios project the same pattern for the east of the region as the $5 \mathrm{~mm}$ threshold map (Fig. 3d), with the increases becoming progressively more marked for the bigger events. The decreases in the number of days in the west of the region become less evident, with the transition zone (very mixed signal) in the western interior now effectively extending through to the west coast.

\section{Potential changes in hydrologically relevant rainfall statistics under a distant future climate}

Since more emphasis was placed in this study on comparing the intermediate future climate to the present climate, only potential changes in mean annual precipitation under the distant future climate are presented here in order to give a general indication of changes in rainfall over the remainder of the century. These changes are presented in Fig. 4 for the regional climate scenarios derived from both AR4 and TAR GCMs. 
e) Total No. of Days with Rainfall > $10 \mathrm{~mm}$
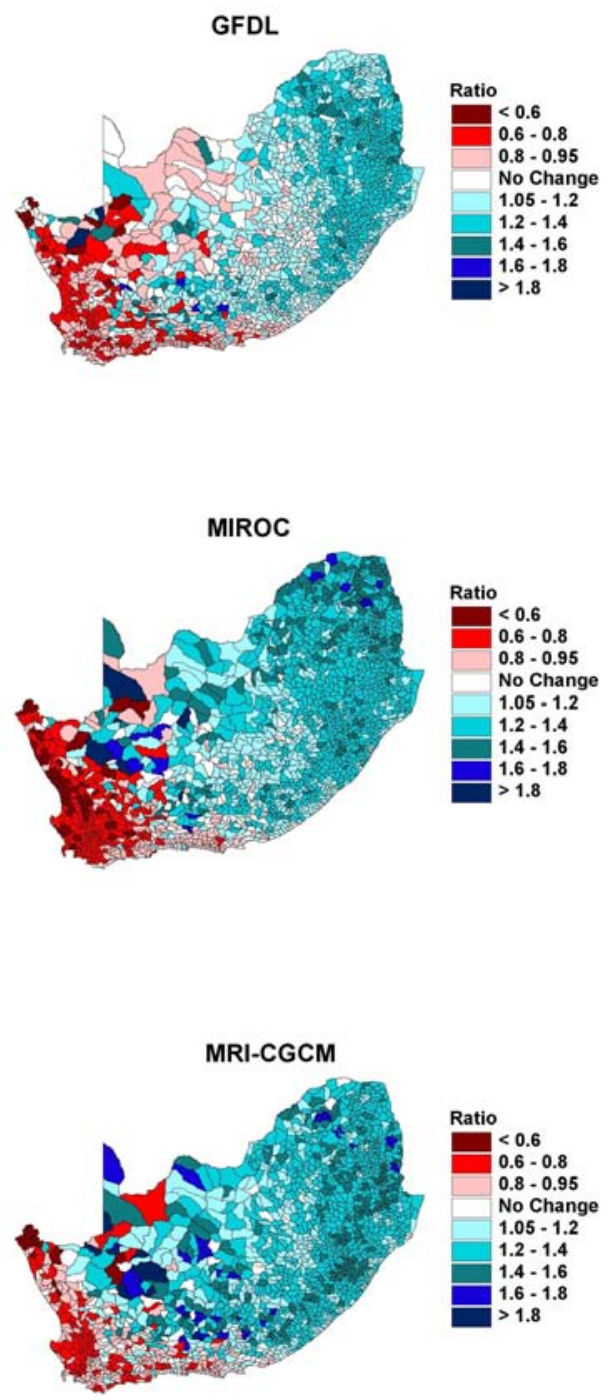

f) Total No. of Days with Rainfall $>20 \mathrm{~mm}$
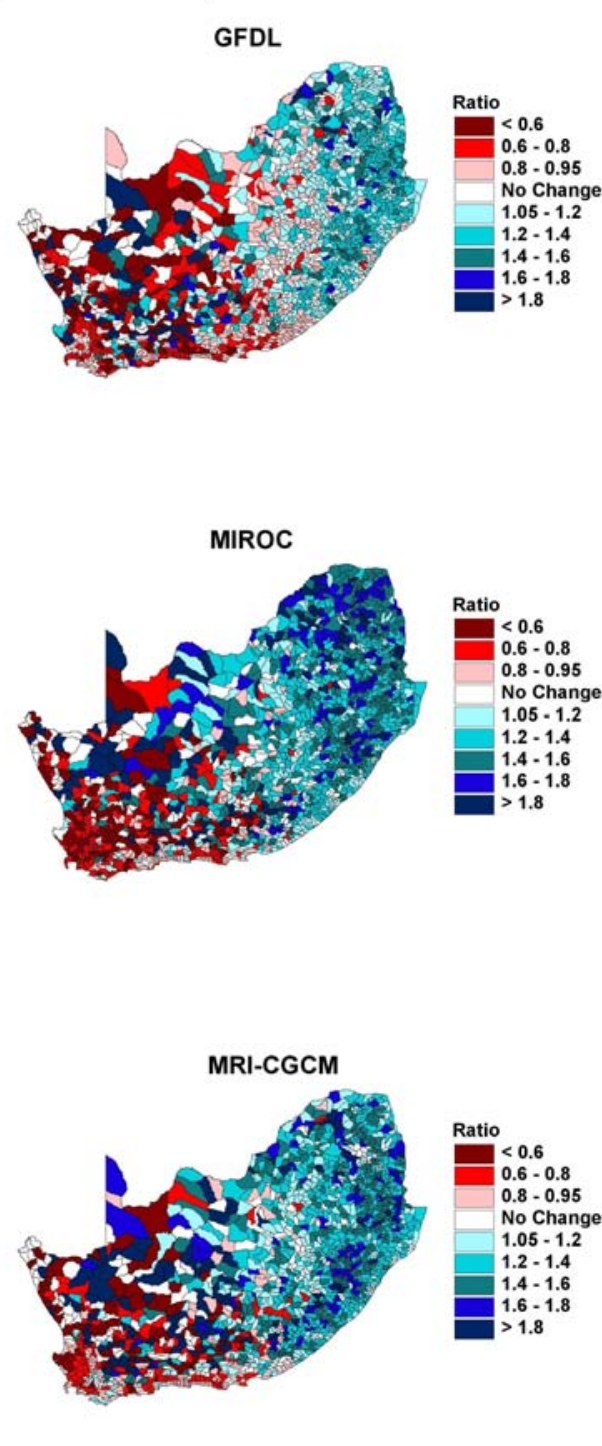

Figure 3 e\&f

Ratios of intermediate future to present climate rainfall statistics: e) total number of days with rainfall $>10 \mathrm{~mm}$ and f) total number of days with rainfall $>20 \mathrm{~mm}$

terms of area and severity than the more recent scenarios derived from the AR4 GCMs considered.

\section{Discussion}

The analysis of rainfall changes in Figs. 3 and 4 has shown that there is more consistency in the patterns for scenarios derived from the AR4 GCMs considered, as opposed to the older ( 2000) TAR GCMs considered. The main differences between the scenarios derived from TAR GCMs (in terms of patterns in MAP for the distant future climate) include the following:

- The strong wetting in the western interior according to the CSIRO-derived scenarios

- The relatively large area in the western and central interior showing no change according to the HadAM-derived scenarios

- The very marked increase in MAP (of more than $80 \%$ ) projected for the extreme eastern parts of the region and parts of the Limpopo Province of South Africa by the ECHAM-derived scenarios.

Although there is greater consistency in the patterns projected by the AR4 GCMs

For the regional climate scenarios derived from the AR4 GCMs considered, the patterns in MAP evident under the intermediate future climate become more pronounced for the distant future climate. For the regional climate scenarios derived from the TAR GCMs considered, there is less consistency in the patterns in MAP under the distant future climate than there is in those scenarios derived from the AR4 GCMs considered. The change in MAP according to the ECHAM derived scenarios shows wetting over almost the whole region, except along the west coast. Some of the wetting is extremely marked, with certain areas projected to receive $80 \%$ more rainfall. The HadAM-derived scenario shows the largest transition zone between eastern and western areas of the region, with the zone extending more eastward than any other model and having more catchments with no change. The CSIRO derived scenario shows a strong wetting pattern in the western interior, whereas other models show a mixed signal transition zone. The scenarios derived from the TAR GCMs considered all show drying in the west of the region, but this is generally less in considered, this cannot necessarily be attributed to the data having originated from the later IPCC study (AR4), since the same GCMs were not considered in both the TAR and AR4 studies. If downscaled data were available for the same GCMs for both the TAR and AR4 studies (or at least for a larger, more representative sample of GCMs for both IPCC assessments), and greater consistency were observed in the AR4 GCMs, then this consistency could be ascribed to the later AR4 study.

According to all of the scenarios evaluated in the study, more rainfall is projected for the east of the region. This rainfall comes in the form of more rain days and more days with bigger rainfalls. If these scenarios are correct, the combination of wetter antecedent conditions and larger rainfall events would result in more runoff being generated and this would have implications for, inter alia, filling of dams. There would also be implications for water quality, and in particular, sediment related water quality which affects, inter alia, water treatment, dam siltation and aquatic ecosystems. The above patterns are projected to extend to the end of the century. It is unclear at this 
stage whether the projected change will be more rapid in the former or latter half of the century.

According to all of the scenarios evaluated, less rainfall is projected along the west coast and the adjacent interior, with the possibility of a slight increase in inter-annual variability. If correct, these patterns would result in a decrease in flows and an increase in flow variability, since changes in precipitation are amplified in the hydrological cycle. It is likely that the mixed signal in the temporal distribution of rainfall would also be reflected in the incidence of stormflow events in this area.

It is significant that the regional climate scenarios evaluated in this paper project much larger increases in rainfall in the east of the region than the scenarios of Engelbrecht (2005), as evaluated by Schulze et al. (2005). The scenarios evaluated in this paper, which were developed over a longer period of time, were produced at a 4 times finer spatial resolution and were also derived from a number of climate models, as opposed to one. The unanimous pattern of wetting in the east projected by the scenarios is noteworthy, and is in agreement with the multi-model mean as projected in the IPCC AR4 for summer.

In contrast to the east of the region, where disparities in projected changes exist between the C-CAM climate scenarios in Engelbrecht (2005) and the scenarios evaluated in this paper, both sources project relatively strong drying along the west coast and adjacent interior. The C-CAM future climate scenarios, like the scenarios evaluated in this paper, were simulated assuming the SRES A2 emissions scenario.

The regional climate scenarios evaluated in this paper project more distinctive patterns in changes in rainfall in the future than has been detected in observed rainfall records for the last century. This might be attributable, in part, to the challenges associated with detecting changes in observed records in South Africa, where these records are characterised by high inter-annual and intra-annual variability (Warburton and Schulze, 2005). The spatial scale of the analyses performed and the methods used are also factors determining the outcome of detection studies (Lloyd, 2009). b) Mean Annual Precipitation: TAR GCMs
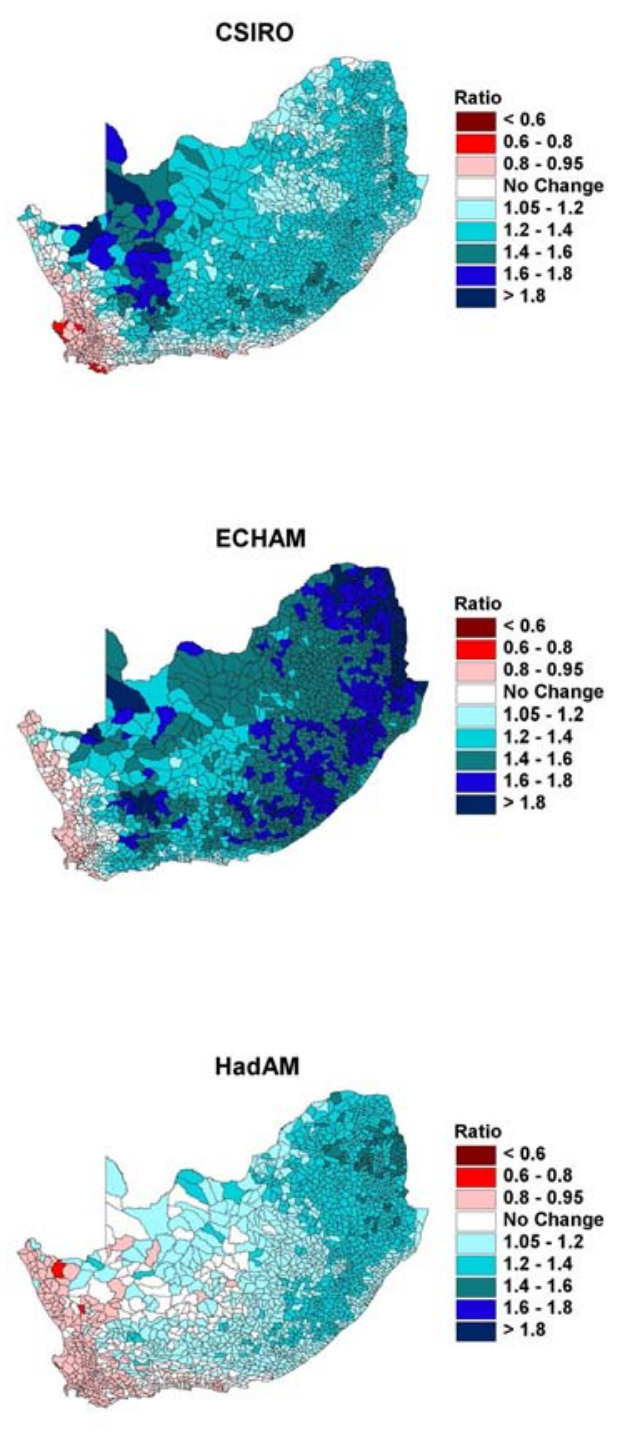

Ratio $<0$. $<0.6$
$0.6-0.8$ $0.8-0.95$ No Change $1.05-1.2$ $1.2-1.4$ $1.4-1.6$
$1.6-1.8$ $>1.8$

Figure 4 derived from a) AR4 and b) TAR general circulation models

\section{Recommendations for further research}

It is recommended that the following be investigated in future research:

- The rate of expected change in the $1^{\text {st }}$ half of this century vs. that in the $2^{\text {nd }}$ half of the century

- Possible shifts in the seasonal timing of rainfall

- Projected changes in extreme rainfall events

- The impact of projected climate change on other climatic variables, e.g. temperature and potential evaporation

- The explicit assessment of the impacts of projected climate change on hydrological responses through the application of climate scenarios in a hydrological model

- The application of alternative emission scenarios in climate scenario development to define the full envelope of possible change.

\section{Conclusion}

The regional scenarios of climate change evaluated in this paper facilitate studies of the impact of climate change on 
water resources to be conducted at a finer spatial scale and with a greater degree of confidence (stemming from the availability of multiple scenarios), than has previously been the case. As convergence becomes apparent, there is now an arguable basis for developing appropriate response strategies for incorporation into adaptation policy. Perhaps one of the greatest challenges in this regard is now to explore the issues of uncertainty and probability in order to develop a more rigorous basis to enable proactive responses. This paper has highlighted preliminary patterns of change that are likely, and has recommended future areas of research in support of efforts to adapt to climate change in the region.

\section{Acknowledgements}

The authors wish to thank the Water Research Commission for funding the research. The modelling groups, the Program for Climate Model Diagnosis and Intercomparison (PCMDI) and the World Climate Research Programme's (WCRPs) Working Group on Coupled Modelling (WGCM) are also thanked for their roles in making available the WCRP CMIP3 multi-model dataset. Support of this dataset is provided by the Office of Science, US Department of Energy.

\section{References}

CHEN M, DICKINSON RE, ZENG X and HAHMANN AN (1996) Comparison of precipitation observed over the continental United States to that simulated by a climate model. J. Clim. 9 (9) 2233-2249.

ENGELBRECHT F (2005) Simulations of climate and climate change over Southern and tropical Africa with the conformal-cubic atmospheric model. In: Schulze RE (ed.) Climate Change and Water Resources in Southern Africa: Studies on Scenarios, Impacts, Vulnerabilities and Adaptation. WRC Report No. 1430/1/05. Chapter 4, 57-74. Water Research Commission, Pretoria, RSA.

FAUCHEREAU N, TRZASKA S, ROUAULT M and RICHARD Y (2003) Rainfall variability and changes in Southern Africa during the 20th century in the global warming context. Nat. Hazards. 29 (2) 139-154.

HEWITSON BC, TADROSS M and JACK C (2005a) Scenarios developed with empirical and regional climate model-based downscaling. In: Schulze RE (ed.) Climate Change and Water Resources in Southern Africa: Studies on Scenarios, Impacts, Vulnerabilities and Adaptation. WRC Report No. 1430/1/05. Chapter 3, 39-56. Water Research Commission, Pretoria, RSA.

HEWITSON BC, TADROSS M and JACK C (2005b) Climate change scenarios: Conceptual foundations, large scale forcing, uncertainty and the climate context. In: Schulze RE (ed.) Climate Change and Water Resources in Southern Africa: Studies on Scenarios, Impacts, Vulnerabilities and Adaptation. WRC Report No. 1430/1/05. Chapter 2, 21 - 38. Water Research Commission, Pretoria, RSA.

IPCC (2001) Climate Change 2001: The Scientific Basis. Contribution of Working Group I to the Third Assessment Report of the
Intergovernmental Panel on Climate Change [Houghton JT, Ding Y, Griggs DJ, Noguer M, van der Linden PJ, Dai X, Maskell K and Johnson CA (eds.)]. Cambridge University Press, Cambridge, United Kingdom and New York, NY, USA. 881 pp.

IPCC (2007) Climate Change 2007: The Physical Science Basis. Contribution of Working Group I to the Fourth Assessment Report of the Intergovernmental Panel on Climate Change [Solomon S, Qin D, Manning M, Chen Z, Marquis M, Averyt KB, Tignor M and Miller HL (eds.)]. Cambridge University Press, Cambridge, United Kingdom and New York, NY, USA. 996 pp.

KIKER G (2000) South African Country Study on Climate Change: Synthesis Report for the Vulnerability and Adaptation Assessment Section. Report to the National Climate Change Committee, Department of Environmental Affairs and Tourism, Pretoria, South Africa. $74 \mathrm{pp}$.

LLOYD P (2009) On the determination of trends in rainfall. Water $S A$ 35 (3) $237-244$

LYNCH SD, ZULU JT, KING KN and KNOESEN DM (2001) The analysis of 74 years of rainfall recorded by the Irwins on two farms south of Potchefstroom. Water SA 27 (4) 559-564.

MACKELLAR NC, HEWITSON BC and TADROSS MA (2007) Namaqualand's climate: Recent historical changes and future scenarios. J. Arid Environ. 70 (4) 604-614.

NAKIĆENOVIĆ N and SWART R (eds.) (2000) Special Report on Emissions Scenarios. A Special Report of Working Group III of the Intergovernmental Panel on Climate Change. Cambridge University Press, Cambridge, United Kingdom and New York, NY, USA. 599 pp.

OSBORN TJ and HULME M (1997) Development of a relationship between station and grid-box rainday frequencies for climate model evaluation. J. Clim. 10 (8) 1885-1908.

PERKS LA, SCHULZE RE, KIKER GA, HORAN MJC AND MAHARAJ M (2000) Preparation of Climate Data and Information for Application in Impact Studies of Climate Change over Southern Africa. Report to South African Country Studies for Climate Change Programme. ACRUcons Report 32. School of Bioresources Engineering and Environmental Hydrology, University of Natal, Pietermaritzburg. 75 pp.

RICHARD Y, FAUCHEREAU N, POCCARD I, ROUAULT M and TRZASKA S (2001) $20^{\text {th }}$ century droughts in southern Africa: Spatial and temporal variability, teleconnections with oceanic and atmospheric conditions. Int. J. Clim. 21 (7) 873-885.

SCHULZE RE, LUMSDEN TG, HORAN MJC, WARBURTON M and MAHARAJ M (2005) An assessment of impacts of climate change on agrohydrological responses over Southern Africa. In: Schulze RE (ed.) Climate Change and Water Resources in Southern Africa: Studies on Scenarios, Impacts, Vulnerabilities and Adaptation. WRC Report No. 1430/1/05. Chapter 9, 141189. Water Research Commission, Pretoria, RSA.

VAN WAGENINGEN A and DU PLESSIS JA (2007) Are rainfall intensities changing, could climate change be blamed and what could be the impact for hydrologists? Water SA 33 (4) 571-574.

WARBURTON M and SCHULZE RE (2005) Historical precipitation trends over Southern Africa: a hydrology perspective. In: Schulze RE (ed.) Climate Change and Water Resources in Southern Africa: Studies on Scenarios, Impacts, Vulnerabilities and Adaptation. WRC Report No. 1430/1/05. Chapter 19, 326-338. Water Research Commission, Pretoria, RSA. 